\title{
Tolerância do Tifton 85 aO Glyphosate em Diferentes Épocas DE APLicaÇÃo
}

\author{
Tifton 85 Tolerance to Glyphosate at Different Application Times
}

\author{
SANTOS, M.V. ${ }^{2}$, FREITAS, F.C.L. ${ }^{3}$, FERREIRA, F.A. ${ }^{4}$, CARVALHO, A.J. ${ }^{5}$, BRAZ, T.G.S. ${ }^{6}$, \\ CAVALI, J. ${ }^{7}$ e RODRIGUES, O.L. ${ }^{8}$
}

\begin{abstract}
RESUMO - O Tifton 85 é uma forrageira de alto valor nutritivo, recomendada para pastejo, fenação e silagem, podendo ser considerada uma espécie daninha, principalmente em áreas de cultivos agrícolas e produção de sementes de outras forrageiras, devido a sua fácil propagação e seu rápido desenvolvimento. Este experimento foi proposto com o objetivo de avaliar a tolerância de plantas de Tifton 85 a doses crescentes de glyphosate em duas épocas diferentes. O experimento foi conduzido em vasos de polietileno com capacidade de $10 \mathrm{~L}$, em delineamento experimental de blocos casualizados, no esquema fatorial 2 x 8 , sendo duas épocas de aplicação (inverno e verão) e oito doses de glyphosate (0, 270, 540, 1.080, 2.160, 3.240 , 4.320 e $5.400 \mathrm{~g} \mathrm{ha}^{-1}$ ), com quatro repetições. Para cada época de aplicação, o controle das plantas de Tifton 85 foi feito aos 15, 30 e 60 DAA (dias após aplicação). Obteve-se controle superior a 90\% de Tifton 85 a partir de 2.636,72 $\mathrm{g}^{\text {ha-1 }}$ de glyphosate em aplicação realizada no inverno e de $3.607,03 \mathrm{~g} \mathrm{ha}^{-1}$ em aplicação no verão. Os resultados evidenciaram a alta tolerância do Tifton 85 ao glyphosate e o maior controle das plantas expostas a esse herbicida em épocas mais frias do ano (inverno), quando em comparação com as plantas expostas ao herbicida no verão.
\end{abstract}

Palavras-chave: Cynodon spp., pastagem, planta daninha, forrageiras.

\begin{abstract}
Tifton 85 is a type of forage of high nutritive value, recommended for grazing or hay and silage production. It can be considered a weed, mainly in agricultural and forage seed production areas, probably due to its easy propagation and fast development. Thus, this experiment aimed to evaluate Tifton 85 tolerance to increasing levels of glyphosate during two different seasons. The experiment was arranged in a completely randomized block design with four replications in a $2 \times 8$ factorial arrangement, and pulverization in two seasons (winter and summer) and eight glyphosate levels (0; 270; 540; 1,080; 2, 160; 3,240; 4,320; and 5, $400 \mathrm{~g} \mathrm{ha}^{-1}$ ). The experiment was carried out in polyethylene pots with $10 \mathrm{~L}$ capacity. For each season, control of the Tifton 85 plants was performed at 15, 30 and 60 DAA (days after application). Around 90\% of Tifton 85 plant control was observed with 2, 636.72 $\mathrm{g} \mathrm{ha}^{-1}$ of glyphosate in the winter and 3,607.03 $\mathrm{g} \mathrm{ha}^{-1}$ of glyphosate in the summer. The results obtained showed that Tifton 85 is highly tolerant to glyphosate and control is more efficient in the winter than in the summer.
\end{abstract}

Keywords: Cynodon spp., pasture, weed, forage.

Recebido para publicação em 28.2.2009 e na forma revisada em 12.3.2010.

2 Doutora em Zootecnia, UFV < marciavitori@hotmail.com>; ${ }^{3}$ Professor Adjunto, Universidade Federal do Semi-Árido - UFERSA; ${ }^{4}$ Professor Titular do Dep. de Fitotecnia - DFT/UFV; ${ }^{5}$ Doutor em Fitotecnia - UFV; ${ }^{6}$ Doutorando em Zootecnia, UFV; ${ }^{7}$ Doutoranda em Zootecnia, UFV; ${ }^{8}$ Doutorando em Fitotecnia, Universidade Federal de Viçosa, Departamento de Fitotecnia, DFT/UFV, ViçosaMG, 36.570-000. 


\section{INTRODUÇÃO}

O gênero Cynodon engloba oito espécies, distribuídas em quatro grupos de acordo com sua distribuição geográfica (Harlan, 1970). Uma outra subdivisão proposta é a de dois grandes grupos dentro do gênero: gramas bermuda (C. dactylon), que incluem plantas rizomatosas (colmos subterrâneos), e gramas estrela (C. nlemfuënsis e C. plectostachyus), que são plantas não rizomatosas e robustas.

Alguns trabalhos reportam problemas causados por plantas do gênero Cynodon em culturas agronômicas, como cana-de-açúcar (Oliveira \& Freitas, 2008), milho (Vaz de Melo et al., 2007), pomares de citros (Martini et al., 2002), batata e soja (Bedmar, 1997).

Algumas espécies do gênero Cynodon possuem grande número de rizomas e estolões efetivos na propagação da espécie, o que dificulta a adoção de métodos mecânicos de controle e inviabiliza o uso de determinados herbicidas (Santos et al., 2008). O uso de produtos à base de glyphosate tem apresentado bons resultados em plantas jovens, porém relatos de tolerância de espécies do gênero Cynodon a esse herbicida são frequentes no campo. Em trabalho com Cynodon dactylon, Johnson (1995) demonstrou que os cultivares Commom, Cheyenne, Tropica e Sahara têm suscetibilidades diferentes a um mesmo herbicida. Para alguns herbicidas recomendase a aplicação sequencial, realizada em plantas jovens e posteriormente em adultas (Santos, 2008), e repetida ao longo dos anos, para o controle de espécies como Cynodon dactylon (Grichar, 1995), sendo o glyphosate indicado para o seu controle.

O glyphosate é um herbicida recomendado para o controle de plantas daninhas monocotiledôneas e dicotiledôneas, sendo utilizado em várias culturas agronômicas e também no controle de forrageiras indesejáveis em áreas de pastagens, como no caso do Tifton $85 \mathrm{em}$ áreas de cultivo agrícola e produção de outras espécies forrageiras. Embora o glyphosate seja um herbicida sistêmico, registrado como não seletivo, alguns estudos relatam a maior tolerância do Tifton 85 a esse herbicida quando em comparação a outras forrageiras, como as do gênero Brachiaria (Santos et al., 2006, 2007, 2008), que também, em determinadas situações, podem ser consideradas plantas daninhas.

O cultivar Tifton 85 é um híbrido interespecífico, resultante do cruzamento entre Tifton 68 (Cynodon nlemfuënsis) e PI 290884 (Cynodon dactylon), um acesso advindo da África do Sul (Burton et al., 1993), sendo recomendado para pastejo, fenação e silagem, com aceitabilidade por bovinos, bubalinos, equídeos, ovinos e caprinos. Apesar de ser considerada uma forrageira de qualidade e valor nutritivo, por apresentar elevado teor de proteína, digestibilidade da matéria seca, além do potencial produtivo (Pedreira \& Tonato, 2007), é uma espécie que pode vir a ser problemática, sobretudo em áreas de cultivos agrícolas e produção de sementes de forrageiras de outras espécies, devido à sua fácil propagação e difícil erradicação (Mitich, 1989).

Fatores como dose aplicada, temperatura (Devine et al., 1983), tamanho das gotas e volume de aplicação (McWhorter \& Hanks, 1993) podem interferir na rebrota de plantas daninhas como o Tifton 85. Condições que favoreçam a fotossíntese podem auxiliar na translocação do glyphosate (Dellacioppa et al., 1986), sendo esse um processo essencial para a eficácia desse herbicida (Wanamarta \& Penner, 1989). Da mesma forma, a absorção e o metabolismo também estão relacionados com a suscetibilidade de uma planta ao glyphosate (Monquero et al., 2004), bem como a época de aplicação.

Dessa forma, este experimento foi proposto com o objetivo de avaliar a tolerância das plantas de Tifton 85 quando submetidas a elevadas doses do glyphosate, em diferentes épocas de aplicação.

\section{MATERIAL E MÉTODOS}

O ensaio foi conduzido em campo, em vasos de polietileno, no campus da Universidade Federal de Viçosa, Viçosa-MG, localizada a $20^{\circ} 45^{\prime}$ de latitude sul, $46^{\circ} 51^{\prime}$ de longitude oeste e $689 \mathrm{~m}$ de altitude. O ensaio foi realizado de julho de 2005 a abril de 2006. Durante o período de avaliação, foram registrados os dados climáticos (Tabela 1).

O delineamento experimental foi em blocos casualizados, no esquema fatorial $2 \times 8$, 
sendo duas épocas de aplicação (inverno e verão) e oito doses de glyphosate: $0,270,540$, 1.080, 2.160, 3.240, 4.320 e $5.400 \mathrm{~g} \mathrm{ha}^{-1}$.

O solo utilizado foi um Latossolo VermelhoAmarelo de textura argilosa. Os resultados da análise química da amostragem de solo, realizada na camada de $0-20 \mathrm{~cm}$, foram: $\mathrm{pH}$ em $\mathrm{H}_{2} \mathrm{O}: 5,43$; P: 1, 15 (Mehlich-1); K: 53,00 $\mathrm{mg} \mathrm{dm}^{-3}$; $\mathrm{Ca}^{+2}: 1,50 ; \mathrm{Mg}^{+2}: 0,63 ; \mathrm{Al}^{+3}: 0,50 \mathrm{cmol}_{\mathrm{c}} \mathrm{dm}^{-3}$ (KCl $1 \mathrm{~mol} \mathrm{~L}^{-1}$ ); CTC (T): 6,41 $\mathrm{cmolc} \mathrm{dm}^{-3}$; soma de bases: $2,26 \mathrm{cmol}_{\mathrm{c}} \mathrm{dm}^{-3} ; \mathrm{H}+\mathrm{Al}$ : $4,15 \mathrm{cmol}_{\mathrm{c}} \mathrm{dm}^{-3}$; e 2,65 dag $\mathrm{kg}^{-1}$ de matéria orgânica e 20,35 de P-rem. Com base nesses resultados, não foi feita a calagem. Após peneirado, o solo foi adubado com $5 \mathrm{~kg}$ de superfosfato simples por $\mathrm{m}^{3}$. Cada parcela foi constituída de um vaso de fundo perfurado com duas plantas de Tifton 85, contendo $10 \mathrm{~L}$ de solo.

O plantio do Tifton 85 foi realizado por meio de propagação vegetativa, a partir de mudas em estado vegetativo, selecionadas no Setor da Agrostologia do Departamento de Zootecnia da UFV, no município de Viçosa. Cada muda era composta de um estolão com ausência de folhas, contendo $0,20 \mathrm{~m}$ de comprimento $\mathrm{e}$ três gemas. Após seleção no campo, foram transplantadas três mudas por vaso, adotandose o mesmo procedimento para todos os vasos. Após o estabelecimento, foi realizado o desbaste, deixando-se duas plantas, mais vigorosas, em cada vaso. As plantas daninhas que

Tabela 1 - Médias mensais da temperatura média diária, precipitação pluvial total mensal e insolação durante os períodos de junho a setembro de 2005 (primeira época aplicação inverno) e de janeiro a abril de 2006 (segunda época - aplicação verão)

\begin{tabular}{|l|c|c|c|}
\hline \multicolumn{1}{|c|}{ Mês } & $\begin{array}{c}\text { Temperatura } \\
\left({ }^{\circ} \mathrm{C}\right)\end{array}$ & $\begin{array}{c}\text { Precipitaçao } \\
\text { pluvial }(\mathrm{mm})\end{array}$ & $\begin{array}{c}\text { Insolação } \\
\text { (horas por dia) }\end{array}$ \\
\hline Junho/05 & 17,0 & 32,7 & 4,9 \\
\hline Julho/05 & 15,8 & 24,5 & 6,0 \\
\hline Agosto/05 & 17,9 & 37,4 & 6,7 \\
\hline Setembro/05 & 19,6 & 67,5 & 3,2 \\
\hline Janeiro/06 & 23,1 & 180,0 & 7,2 \\
\hline Fevereiro/06 & 23,6 & 84,8 & 9,4 \\
\hline Março/06 & 22,6 & 186,5 & 5,6 \\
\hline Abril/06 & 20,7 & 56,0 & 5,3 \\
\hline
\end{tabular}

ocorreram nas unidades experimentais foram eliminadas manualmente, a fim de observar o efeito dos tratamentos apenas na espécie forrageira. A cada 14 dias foram efetuadas adubações em cobertura, com $2 \mathrm{~g}$ da fórmula N-P-K (20-05-20) por vaso. A irrigação foi realizada diariamente, mantendo-se a umidade do solo próximo a $80 \%$ da capacidade de campo.

A aplicação do glyphosate foi realizada no inverno (7 de junho de 2005) e no verão (8 de janeiro de 2006), quando as plantas de Tifton 85 apresentavam $0,40 \mathrm{~m}$ de altura, utilizando um pulverizador costal, munido com barra contendo dois bicos de jato plano ("leque") XR 11002 , espaçados entre si de $0,5 \mathrm{~m}$, proporcionando volume de calda equivalente a $250 \mathrm{~L} \mathrm{ha}^{-1}$. Durante a aplicação manteve-se a altura da barra a $0,50 \mathrm{~m}$ do alvo e a pressão de $180 \mathrm{kPa}$ à pressão constante (mantida pelo $\mathrm{CO}_{2}$ comprimido). O produto comercial utilizado foi o Roundup original, na concentração de $360 \mathrm{~g} \mathrm{~L}^{-1}$ de glyphosate.

Para cada época de aplicação foram realizadas avaliações do controle das plantas de Tifton 85 aos 15, 30 e 60 dias após aplicação (DAA), por meio de observações visuais, utilizando-se a escala de 0 a 100 , em que 0 corresponde à ausência de controle e 100 ao controle total da espécie. O controle total (100\%) foi caracterizado pela ausência de folhas e perfilhos verdes e ausência de brotações. Aos 60 DAA, as plantas foram cortadas ao nivel do solo e secas em estufa de renovação forçada de ar por $70 \pm 3{ }^{\circ} \mathrm{C}$, até peso constante. Após o corte, os vasos continuaram sendo irrigados, para verificar a possivel rebrota das plantas. Aos 60 dias após o corte (DAC), as plantas rebrotadas foram cortadas e secas em estufa, com os mesmos procedimentos descritos para os 60 DAA, a fim de elucidar o potencial de rebrota e eficiência do controle após 120 DAA.

Os dados obtidos foram submetidos às análises de variância; os efeitos das doses de glyphosate e a interação entre os fatores dose e época de aplicação foram analisados pelo teste $\mathrm{F}$ a $5 \%$ de probabilidade. Da interação entre os fatores estudados foram realizados os desdobramentos das doses dentro de cada período de avaliação, por meio de análise de regressão. 


\section{RESULTADOS E DISCUSSÃO}

A eficiência do glyphosate no controle de Tifton 85 foi influenciada pelas doses utilizadas $(P<0,05)$ nas duas épocas de aplicação (Figuras 1 e 2). Controle superior a 90\% foi observado a partir das doses de 3.839,06 $\mathrm{g} \mathrm{ha}^{-1}$ aos 30 DAA e 2.636,72 $\mathrm{g} \mathrm{ha}^{-1}$ aos 60 DAA, quando da aplicação do glyphosate no inverno (Figura 1). Intoxicação semelhante foi relatada por Martini et al. (2002), testando diferentes formulações de glyphosate amínico no controle de grama-seda (Cynodon dactylon) em pomares de citros, tendo observado $69,4 \%$ aos 43 dias após aplicação do herbicida na dose de $2.160 \mathrm{~g}$ ha ${ }^{1}$. Segundo esses autores, a indicação do glyphosate potássico (a $2.100 \mathrm{~g} \mathrm{ha}^{-1}$ ), de sulfosate (a $1.980 \mathrm{~g} \mathrm{ha}^{-1}$ ) e do glyphosate amínico $\left(2.160 \mathrm{~g} \mathrm{ha}^{-1}\right)$ permite a rebrota e a reinfestação é mais precoce, com necessidade de reaplicação para a manutenção dos bons níveis de controle.

Para aplicações de glyphosate realizadas no verão, niveis superiores a 90\% de controle foram verificados a partir da dose de 4.366,41 $\mathrm{g} \mathrm{ha}^{-1}$ aos 30 DAA e com $3.607,03 \mathrm{~g} \mathrm{ha}^{-1}$ aos 60 DAA (Figura 2). Esses resultados demonstram a tolerância do Tifton 85 ao glyphosate, sendo ela maior em plantas que foram submetidas ao herbicida após o crescimento em épocas mais quentes do ano

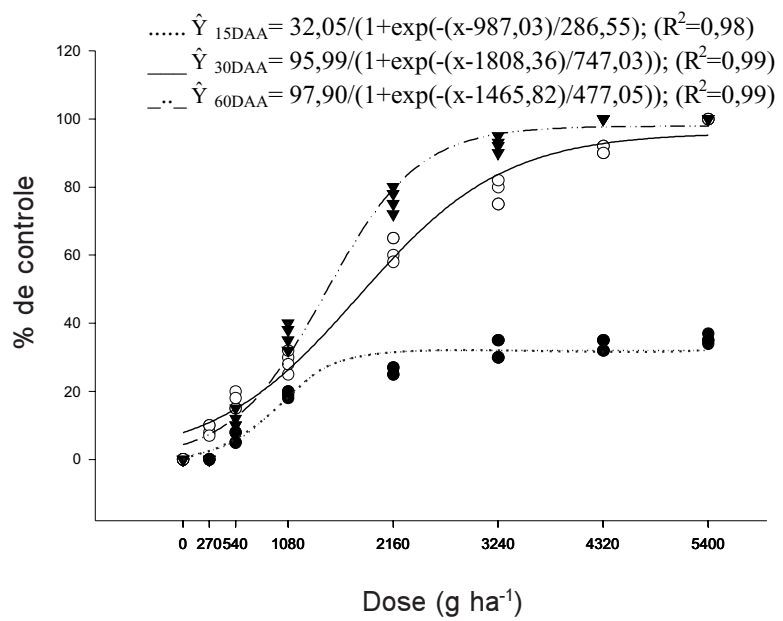

Figura 1 - Porcentagem de controle das plantas de Cynodon spp. (Tifton 85) aos 15, 30 e 60 dias após a aplicação (DAA), em função das doses de 0, 270, 540, 1.080, 2.160, 3.240, 4.320 e $5.400 \mathrm{~g} \mathrm{ha}^{-1}$ do herbicida glyphosate, para a primeira época de aplicação (inverno). (verão). Isso se deve possivelmente às condições edafoclimáticas mais adequadas a essa espécie forrageira nessa época do ano. Fatores como temperatura e insolação (Tabela 1) podem ter contribuído para maior recuperação das plantas nessas condições, quando em comparação à primeira época de aplicação (inverno).

Os valores de massa seca variaram entre as diferentes doses testadas $(\mathrm{P}<0,05)$, aos 60 DAA e na rebrota aos 60 DAC, sendo as médias e suas comparações apresentadas na Tabela 2. Nessa tabela, aos 60 DAA e 60 DAC, houve redução na produção de massa seca de Tifton 85 com o aumento das doses do herbicida aplicado. Quando a aplicação foi realizada no inverno (primeira época), observou-se aos 60 DAA redução de $93 \%$ na produção de massa de forragem das plantas submetidas à dose de $2.160 \mathrm{~g} \mathrm{ha}^{-1}$, quando em comparação à testemunha (sem aplicação), e ausência de rebrota a partir de $3.240 \mathrm{~g} \mathrm{ha}^{-1}$ de glyphosate (Figura 3). $\mathrm{Na}$ aplicação realizada no verão (segunda época), observou-se aos 60 DAA uma queda de apenas $14 \%$ na produção de massa de forragem na dose de $2.160 \mathrm{~g} \mathrm{ha}^{-1}$ e de $85 \%$ para as plantas submetidas à dose de $4.320 \mathrm{~g} \mathrm{ha}^{-1}$, quando em comparação à testemunha (sem aplicação), e ausência de produção de massa seca e rebrota das plantas de Tifton 85 apenas a partir da dose de $5.400 \mathrm{~g} \mathrm{ha}^{-1}$ de glyphosate (Figura 4).

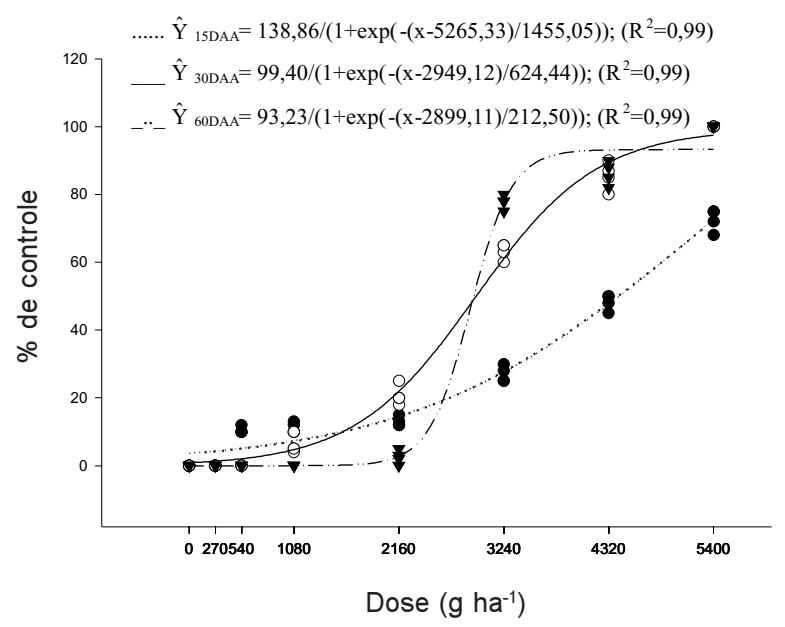

Figura 2 - Porcentagem de controle das plantas de Cynodon spp. (Tifton 85) aos 15, 30 e 60 dias após a aplicação (DAA), em função das doses de 0, 270, 540, 1.080, 2.160, 3.240, 4.320 e $5.400 \mathrm{~g} \mathrm{ha}^{-1}$ do herbicida glyphosate, para a segunda época de aplicação (verão). 
Segundo Martini et al. (2002), a grande quantidade de estolões e rizomas por onde o herbicida tem de distribuir-se após ser absorvido pelas folhas é uma das razões para a necessidade de maiores dosagens para a obtenção de resultados consistentes de controle de espécies do gênero Cynodon.

Tabela 2 - Valores médios de massa seca de plantas de Cynodon spp. (Tifton 85), submetidas às doses de 0, 270, $540,1.080,2.160,3.240,4.320$ e $5.400 \mathrm{~g} \mathrm{ha}^{-1}$ do glyphosate, aos 60 dias após aplicação (DAA) e na rebrota aos 60 dias após o corte (DAC), para as duas épocas de controle

\begin{tabular}{|c|c|c|c|c|}
\hline \multirow{2}{*}{$\left.\begin{array}{c}\text { Glyphosate } \\
\text { Dose } \\
(\mathrm{g} \mathrm{ha}\end{array}{ }^{-1}\right)$} & \multicolumn{2}{|c|}{$\begin{array}{c}\text { Primeira época } \\
\text { (aplicação no inverno) }\end{array}$} & \multicolumn{2}{c|}{$\begin{array}{c}\text { Segunda época } \\
\text { (aplicação no verão) }\end{array}$} \\
\cline { 2 - 5 } & \multicolumn{3}{|c|}{ Massa seca Tifton 85 (g por vaso) } \\
\cline { 2 - 5 } & $60 \mathrm{DAA}$ & $\begin{array}{c}60 \mathrm{DAC} \\
\text { (Rebrota) }\end{array}$ & $60 \mathrm{DAA}$ & $\begin{array}{c}60 \mathrm{DAC} \\
\text { (Rebrota) }\end{array}$ \\
\hline 0 & $93,92 \mathrm{a}$ & $71,38 \mathrm{a}$ & $108,40 \mathrm{a}$ & $66,12 \mathrm{bc}$ \\
\hline 270 & $82,55 \mathrm{~b}$ & $68,88 \mathrm{a}$ & $111,76 \mathrm{a}$ & $80,10 \mathrm{a}$ \\
\hline 540 & $61,86 \mathrm{c}$ & $58,96 \mathrm{~b}$ & $105,60 \mathrm{ab}$ & $71,55 \mathrm{~b}$ \\
\hline 1.080 & $31,65 \mathrm{~d}$ & $50,60 \mathrm{c}$ & $95,55 \mathrm{bc}$ & $63,53 \mathrm{c}$ \\
\hline 2.160 & $6,73 \mathrm{e}$ & $25,05 \mathrm{~d}$ & $93,00 \mathrm{c}$ & $70,55 \mathrm{~b}$ \\
\hline 3.240 & $0,00 \mathrm{e}$ & $0,00 \mathrm{e}$ & $28,51 \mathrm{~d}$ & $40,23 \mathrm{~d}$ \\
\hline 4.320 & $0,00 \mathrm{e}$ & $0,00 \mathrm{e}$ & $16,71 \mathrm{e}$ & $27,63 \mathrm{e}$ \\
\hline 5.400 & $0,00 \mathrm{e}$ & $0,00 \mathrm{e}$ & $0,00 \mathrm{f}$ & $0,00 \mathrm{f}$ \\
\hline $\mathrm{CV}(\%)$ & 12,56 & 9,30 & 10,65 & 7,24 \\
\hline
\end{tabular}

Médias seguidas pelas mesmas letras na coluna não diferem entre si pelo teste de Duncan a $5 \%$ de probabilidade.
Embora o controle de Tifton 85 em plantas submetidas ao glyphosate no verão fosse superior a $90 \%$ a partir das doses de 3.607,03 $\mathrm{g} \mathrm{ha}^{-1}$ aos 60 DAA (Figura 2), como encontrado na análise de regressão, observou-se aos 60 DAC recuperação das plantas (rebrota) na dose de $4.320 \mathrm{~g} \mathrm{ha}^{-1}$ (Figura 4). Como reportado por Santos et al. (2006, 2007, 2008), as plantas de Tifton 85 tendem a apresentar no verão maior tolerância ao herbicida glyphosate, em razão, possivelmente, das condições favoráveis ao crescimento e desenvolvimento, como a temperatura, o que pode estar relacionado à maior facilidade de metabolização, conjugação e/ou exsudação do herbicida pelas plantas, além do maior desenvolvimento de rizomas ricos em amido, servindo de reservas para recuperação das plantas. Segundo Monquero et al. (2004), em condições favoráveis, o glyphosate penetra rapidamente nas folhas e, em algumas espécies de plantas, é metabolizado, enquanto em outras ele é detectado como molécula intacta. Essas diferenças podem ocorrer por diversas razões, e pesquisas usando técnicas de análise e identificação mais apuradas são necessárias para estabelecer se esses efeitos ocorrem realmente devido a um metabolismo diferencial do glyphosate.

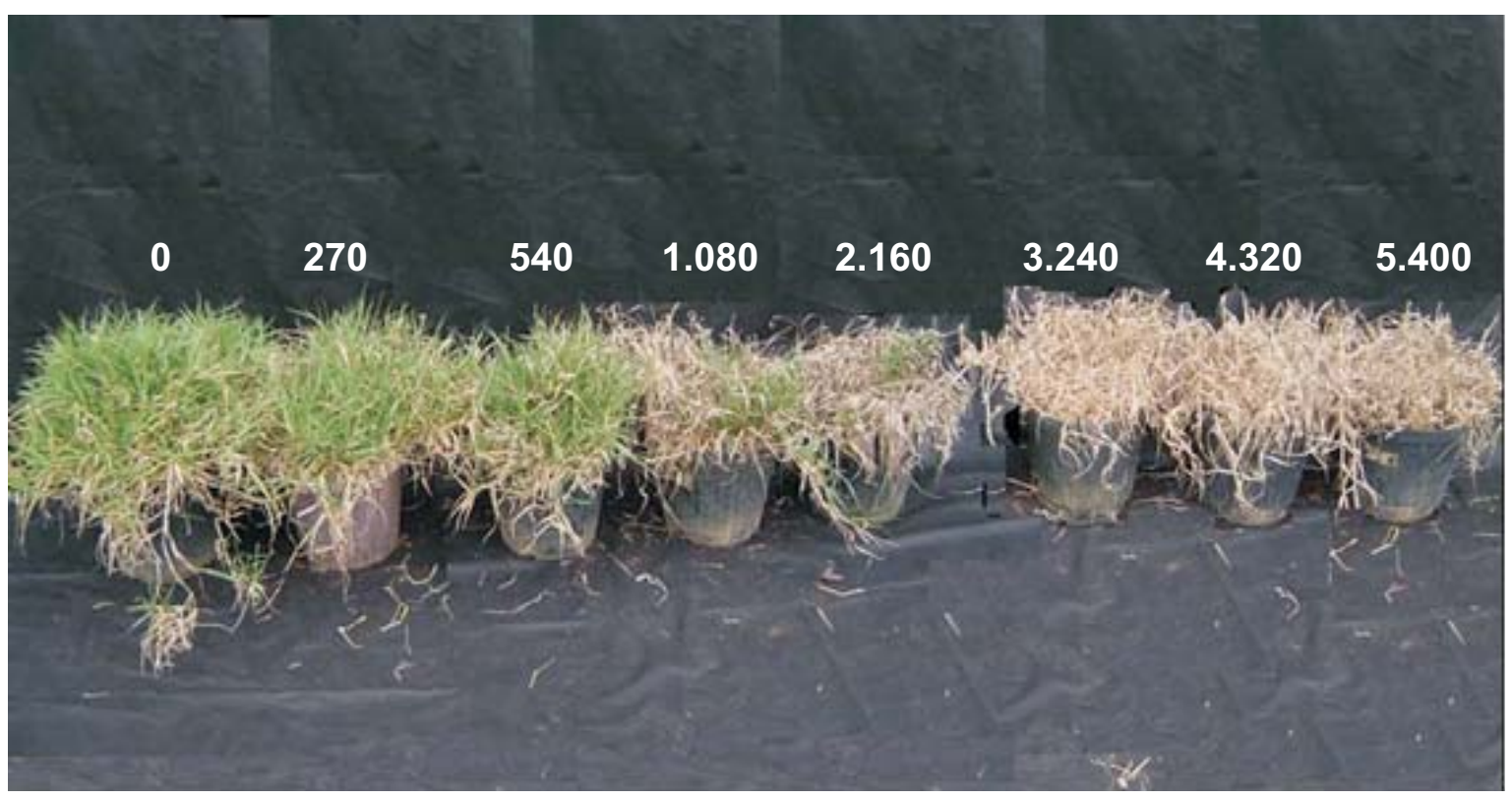

Figura 3 - Controle de Cynodon spp. (Tifton 85) aos 60 dias após a aplicação (DAA), em função das doses de 0, 270, 540, $1.080,2.160,3.240,4.320$ e $5.400 \mathrm{~g} \mathrm{ha}^{-1}$ do herbicida glyphosate, para a primeira época de aplicação (inverno). 

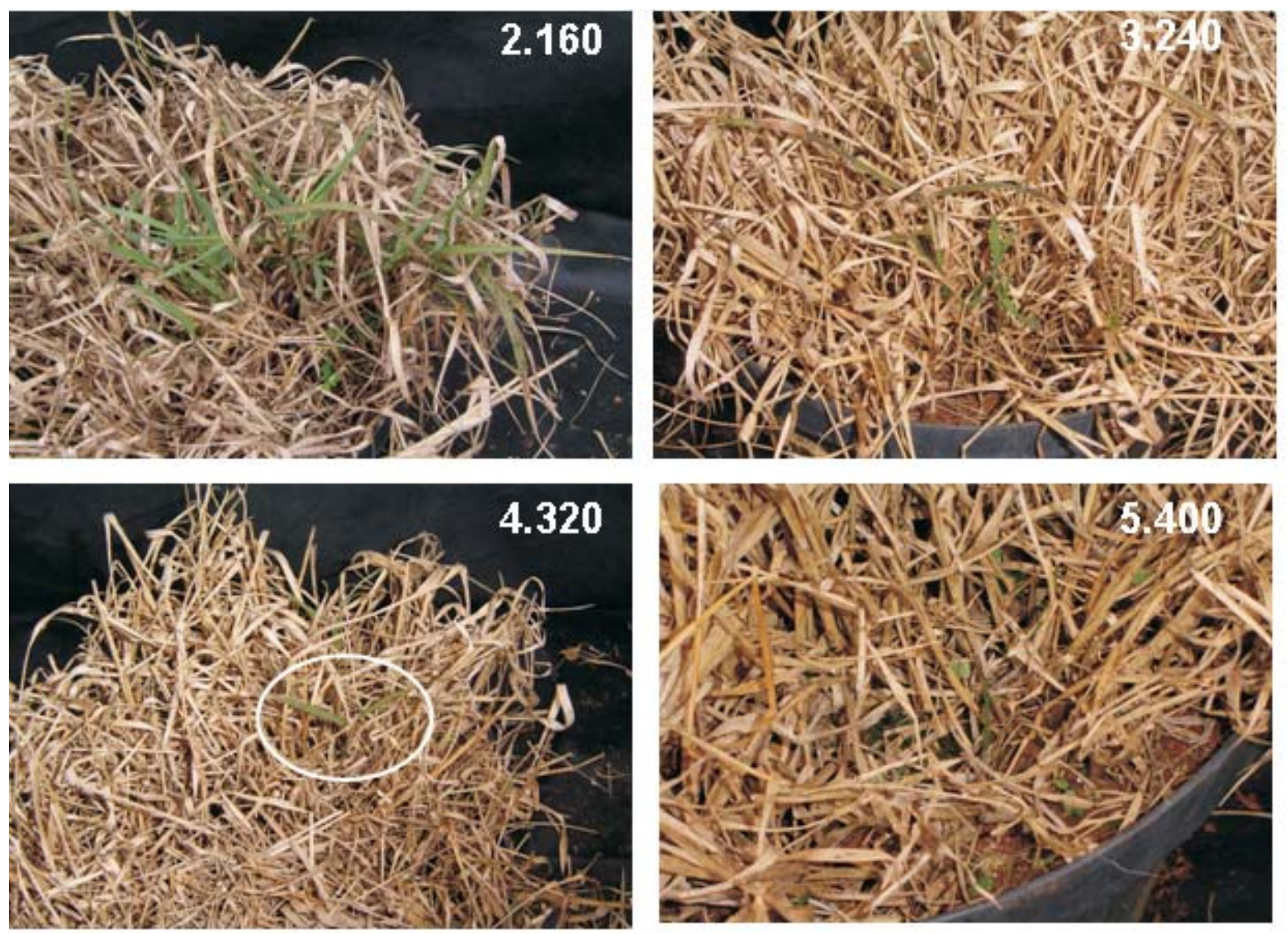

Figura 4 - Ilustração da rebrota das plantas de Cynodon spp. (Tifton 85) aos 60 dias após a colheita (DAC), em função das doses de $2.160,3.240,4.320$ e $5.400 \mathrm{~g} \mathrm{ha}^{-1}$ do herbicida glyphosate, para a segunda época de aplicação (verão), e detalhe da rebrota na dose de $4.320 \mathrm{~g} \mathrm{ha}^{-1}$ (círculo).

Os resultados evidenciaram a alta tolerância do Tifton 85 ao glyphosate e o maior controle das plantas expostas a esse herbicida em épocas mais frias do ano (inverno), quando em comparação às plantas expostas ao herbicida no verão.

\section{LITERATURA CITADA}

BEDMAR, F. Bermudagrass (Cynodon dactylon) control in sunflower (Helianthus annuus) soybean (Glycine max) and potato (Solanun tuberosum) with postemergence graminicides. Weed Technol., v. 11. n. 44, p. 683-688, 1997.

BURTON, G. W.; GATES, R. N.; HILL, G. M. Registration of 'Tifton 85' bermudagrass. Crop Sci., v. 33, n. 3, p. 644-645, 1993.

DELLACIOPPA, G. et al. Translocation of the precursor of 5-enolpyruvylshikimate-3-phosphate synthase into chloroplasts of higher plants in vitro. Proc. Nat. Acad. Sci., v. 83 , n. 18 , p. $6973-6977,1986$
DEVINE, M. D.; BANDEEN, J. D.; MCKERSIE, B. D. Temperature effects on glyphosate absorption, translocation and distribution in quackgrass (Agropyron repens).

Weed Sci., v. 31, p. 461-464, 1983.

GRICHAR, W. J. Comparison of postemergence herbicides for common bermudagrass (Cynodon dactylon) control in peanut (Arachis hypogea). Weed Technol., v. 9, n. 44, p. 825-828, 1995.

HARLAN, J. R. Gênero Cynodon. Review article. Herbage Abstracts, v. 40, n. 3, p. 233-238, 1970.

JOHNSON, B. J. Tolerance of four seeded commom bermudagrass (Cynodon dactylon) types to herbicides. Weed Technol., v. 9, n. 44, p. 794-800, 1995.

MARTINI, G. et al. Eficácia de uma nova formulação de glifosato para o controle de grama-seda (Cynodon dactylon), em pomar de citros. R. Bras. Frutic., v. 24, n. 3, p. 683-686, 2002. 
MCWHORTER, C. G.; HANKS, J. E. Effect of spray volume and pressure on postemergence johnsongrass (Sorghum halepense) control. Weed Technol., v. 7, p. 304-310, 1993.

MITICH, L. W. Bermudagrass. Weed Technol., v. 3., p. $433-435,1989$.

MONQUERO, P. A. et al. Absorção, translocação e metabolismo do glyphosate por plantas tolerantes e susceptíveis a este herbicida. Planta Daninha, v. 22, n. 3, p. 445-451, 2004.

OLIVEIRA, A. R.; FREITAS, S. P. Levantamento fitossociológico de plantas daninhas em áreas de produção de cana-de-açúcar. Planta Daninha, v. 26, n. 1, p. 33-46, 2008.

PEDREIRA, C. G. S.; TONATO, F. Uso de gramíneas do gênero Cynodon como alternativa na formação de pastagens abordagem e implicações econômicas. In: SIMPÓSIO DE FORRAGICULTURA E PASTAGENS, 6., 2007, Lavras. Anais... Lavras: 2007. p. 49-84.
SANTOS, M. V. et al. Controle de Brachiaria brizantha com uso do glyphosate após o estabelecimento de Tifton 85 (Cynodon spp.). Planta Daninha, v. 24, n. 4, p. 813-819, 2006.

SANTOS, M. V. et al. Controle de Brachiaria brizantha, com uso do glyphosate, na formação de pastagem de Tifton 85 (Cynodon spp.). Planta Daninha, v. 25, n. 1, p. 149-155, 2007.

SANTOS, M. V. et al. Tolerância do Tifton 85 (Cynodon spp.) e da Brachiaria brizantha ao glyphosate.

Planta Daninha, v. 26, n. 2, p. 353-360, 2008

VAZ DE MELO, A. et al. Dinâmica populacional de plantas daninhas em cultivo de milho-verde nos sistemas orgânico e tradicional. Planta Daninha, v. 25, n. 3, p. 521-527, 2007.

WANAMARTA, G. D.; PENNER, D. Foliar absorption of herbicides. Weed Sci., v. 4, p. 215-31, 1989. 